Research Article

\title{
Cable Force Identification Based on Bending Waves in Substructures
}

\author{
Jing Huang, ${ }^{1,2}$ Jun Xiao,, ${ }^{3,4}$ Jinxiang Zhang, ${ }^{5}$ Fanying Jiang, ${ }^{5}$ Yang Dai, ${ }^{6}$ \\ and Mingjin Zhang ${ }^{5}$ \\ ${ }^{1}$ Dongfang Electric Engineering \& Consulting Co., Ltd., Chengdu 611731, China \\ ${ }^{2}$ School of Civil Engineering, Chongqing University, Chongqing 400045, China \\ ${ }^{3}$ CCCC Second Highway Engineering Co., Ltd., Xi'an 710064, China \\ ${ }^{4}$ School of Highway, Chang'an University, Xi'an 710064, China \\ ${ }^{5}$ Department of Bridge Engineering, Southwest Jiaotong University, Chengdu 610031, Sichuan, China \\ ${ }^{6}$ School of Civil Engineering, Chongqing Jiaotong University, Chongqing 400074, China \\ Correspondence should be addressed to Mingjin Zhang; zhang108119@163.com
}

Received 17 April 2020; Revised 30 July 2020; Accepted 11 August 2020; Published 21 August 2020

Academic Editor: Matteo Strozzi

Copyright (C) 2020 Jing Huang et al. This is an open access article distributed under the Creative Commons Attribution License, which permits unrestricted use, distribution, and reproduction in any medium, provided the original work is properly cited.

A method is proposed to study the dynamic characteristics of cable structures from the perspective of traveling waves based on the modified Timoshenko beam axial tension model. Considering the propagation characteristics of the bending wave in a beam structure, once the frequency response of the three measuring points is measured, the wave component coefficients can be obtained by the least squares method, and then the cable force and bending stiffness can be identified with the aim of minimizing the fitting residual. The accuracy of this method is verified by a numerical simulation experiment of the cable vibration. Compared with the traditional frequency method, this method focuses on the cable force identification of the substructure, so the effect of the shock absorber is invalid. Moreover, the cable force of each position of the cable can be calculated reversely by static analysis with the identified cable force of the substructure, which breaks the concept that the cable force is a single value. Furthermore, the cable force can be identified at each frequency sampling point, reducing the impact of the external disturbance.

\section{Introduction}

The cable is the core component of the cable-stayed bridge. The accurate identification of the cable force is of great importance in bridge construction and operation. The conventional methods to measure the cable force in civil engineering structures include the pressure gauge method, pressure sensor method $[1,2]$, wave method, magnetic flux method, and vibration-based method [3]. The frequency method with the widest range $[4,5]$ depends on the natural frequency of the cable to identify the cable force. Thus, the accuracy of the method depends entirely on the calculation formula under the condition of an accurate frequency measurement. The taut string model was the first cable model used in vibration-based cable tension estimation methods. Assuming a hinged end condition for both cable ends and ignoring the cable bending stiffness, the taut string model results in a large deviation between the actual cable tensions and the cable tensions estimated by the vibrationbased method [6, 7]. Thereafter, many scholars studied the sag and bending stiffness of the cable to improve the accuracy of the vibration-based cable tension estimation method. However, because the essence of cable force identification is based on the structural modal characteristics, the effects of the bending stiffness, boundary conditions and sag are significant, which only leads to a reasonable range for identifying the flexural stiffness of cables. Additionally, the theoretical calculation formula had not been derived; instead, it became the target to be identified $[8,9]$.

In previous studies $[9,10]$, considerable fundamental analyses have been performed on different cable boundary conditions. Because of the complex connection between 
the cable and main beam or tower, the connection mode is between the hinge and consolidation. Although it is feasible to simulate the boundary conditions with the spring stiffness in the static analysis, the stiffness of the dynamic boundary is obviously dependent on the frequency in the dynamic analysis, so the truncating boundary is still insufficient. The cable force is not a fixed value but is a distribution function along the cable length because of the sag of the cable, which cannot be achieved by the traditional cable force identification method. For the frequency method based on the modal characteristics listed above, there were still some problems after longterm research, so some scholars turned to the perspective of traveling waves to study cable force identification. McDanieland Shepard [11] derived the general solution of the dynamic response of the beam. Instead of directly establishing the characteristic equation through the boundary conditions to calculate the unknown coefficients, they were obtained by using the frequency response of different measuring points. Maes et al. [12] then attended to the one-to-one correspondence between the axial force of the beam and the wavenumber and applied the wavenumber identification to the axial force identification of beam. Since the distributed axial force can be approximated as a single value only in the local area for the cable, the identification of the internal force state of the whole cable demands further discussion. Zhang [13] proposed a new theory of cable force identification in his doctoral dissertation by using the Timoshenko beam model to deduce the frequency domain solution of cable vibration, which could calculate the frequency domain response of the cable and by spectral element programming. In his paper, the four-wave components existing in the beam model are not discussed; instead, five points of subcable segment are selected for least squares solution of the wave component coefficient [14], taking wave component coefficient of fitting residual error minimum as a criterion of cable force identification. Moreover, the wavenumber solution of the Euler-Bernoulli beam model is still adopted for the wave components introduced into the cable force identification. Obviously, the accuracy cannot be satisfied in high-frequency response.

In this paper, the beam element is modified to solve the inapplicability of the Euler-Bernoulli beam model for short thick beams and high-frequency segments and to avoid the problems of the Timoshenko beam model of the cutoff frequency and two wave velocity systems. Then, the characteristics of the four waves in the beam model are discussed. It is considered that the near-field wave decays exponentially from the anchorage end to the beam and only exists in the local position of beam anchorage. This phenomenon decays faster with increasing frequency. After neglecting the nearfield wave, the frequency response of the three measuring points is more suitable for the engineering situation. The wave component coefficient is obtained by the least squares fitting method [15-17], and the cable force and bending stiffness are identified with the least fitting residual. Finally, the accuracy of this method is verified by the numerical simulation of the cable vibration.

\section{Dispersion Relation of the Cable Vibration}

2.1. Corrected Timoshenko Beam Theory. Doyle [18] deduced the dispersion relation of the Euler-Bernoulli beam theory, and Lee et al. [19] derived the dispersion relation of the vibration under the Timoshenko beam theory by considering the shear deformation and axial tension. However, the Euler-Bernoulli beam model has a large error at a high frequency due to neglecting the shear deformation, and the existence of a cutoff frequency in Timoshenko beam theory renders two wave velocity systems, which is not consistent with reality. In fact, in the derivation of the Timoshenko beam theory, the moment of inertia caused by shear deformation is not taken into account. Once considered, the cutoff frequency would be eliminated, leaving only one wave velocity system, and the accuracy of the high-frequency vibration response of the structure was increased [20].

When the moment of inertia caused by shear deformation is introduced into the infinitesimal section of the cable, the equilibrium state is shown in Figure 1.

According to Figure 1, the equilibrium equation of the infinitesimal section of the cable is established:

$$
\begin{gathered}
\frac{\partial Q_{y}}{\partial x} \mathrm{~d} x+\frac{\partial}{\partial x}\left[N_{x} \frac{\partial y(x, t)}{\partial x}\right] \mathrm{d} x-\rho A \frac{\partial^{2} y(x, t)}{\partial t^{2}} \mathrm{~d} x=0, \\
\frac{\partial M_{z}}{\partial x} \mathrm{~d} x+Q_{y} \mathrm{~d} x-\rho I \frac{\partial^{2} \eta(x, t)}{\partial t^{2}} \mathrm{~d} x-\rho I \frac{\partial^{2} \lambda(x, t)}{\partial t^{2}} \mathrm{~d} x=0,
\end{gathered}
$$

where $\mathrm{d} x$ is the length of the infinitesimal section along the $x$-axis, $A$ is the sectional area of the cable, and $\rho$ is the density of the cable, $y(x, t)$ is the lateral displacement of the cable, and $\eta(x, t)$ and $\lambda(x, t)$ are the sectional angles caused by the bending and shearing of the cable.

From the Timoshenko beam theory, the shear force $Q_{y}$, bending moment $M_{\mathrm{z}}$, and lateral displacement $y(x, t)$ have the following relations:

$$
\begin{gathered}
Q_{y}=\kappa G A\left(\frac{\partial y}{\partial x}-\theta\right), \\
M_{Z}=E I \frac{\partial \theta}{\partial x}
\end{gathered}
$$

where $E$ is the elastic modulus of the cable and $\kappa$ is the shear deformation coefficient of the section. For cables with a circular cross section, $\kappa$ is calculated as follows:

$$
\kappa=\frac{6(1+\mu)^{2}}{8 \mu^{2}+14 \mu+7}
$$

where $G$ is the shear modulus of the material. For isotropic materials, $G$ is calculated as follows:

$$
G=\frac{E}{2(1+\mu)},
$$

where $\mu$ is the Poisson ratio of the material.

By substituting equations (2)-(5) into equation (1) and performing Fourier transform, the lateral vibration equation 


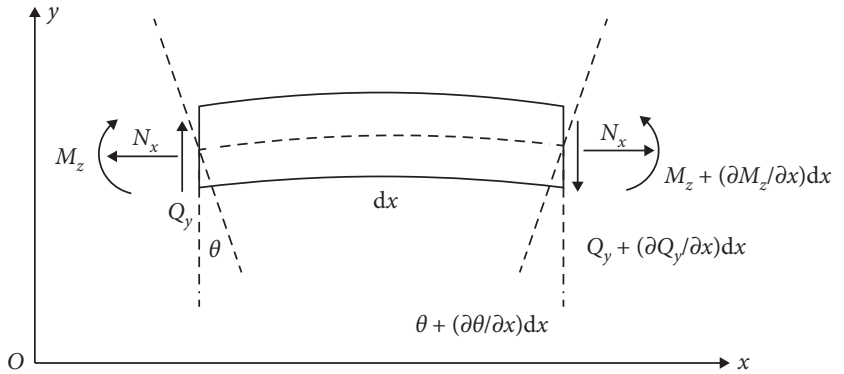

Figure 1: Cable balance diagram.

of the cable in the frequency domain can be written as follows:

$$
\begin{aligned}
& \kappa G A\left[\frac{\partial \hat{\lambda}(x, \omega)}{\partial x}\right]+N_{x} \frac{\partial^{2} Y(x, \omega)}{\partial x^{2}}+\omega^{2} \rho A Y(x, \omega)=0, \\
& E I \frac{\partial^{2} \hat{\eta}(x, \omega)}{\partial x^{2}}+\kappa G A[\hat{\lambda}(x, \omega)]+\omega^{2} \rho I \hat{\eta}(x, \omega)+\omega^{2} \rho I \hat{\lambda}(x, \omega)=0,
\end{aligned}
$$

where $\omega$ is the angular frequency of the cable, $\bar{\eta}(x, \omega)$ is the Fourier transform of $\eta(x, t)$, and $\bar{\lambda}(x, \omega)$ is the Fourier transform of $\lambda(x, t)$ and :

$$
\frac{y(x, t)}{\partial x}-\eta(x, t)-\lambda(x, t)=0 .
$$

After the Fourier transform, the following can be obtained:

$$
\frac{Y(x, \omega)}{\partial x}-\bar{\eta}(x, \omega)-\bar{\lambda}(x, \omega)=0 .
$$

If the solution of equation (6) is $Y(x, \omega)=C \exp (k x)$, $\hat{\eta}(x, \omega)=D \exp (k x)$, and $\bar{\lambda}(x, \omega)=Z \exp (k x)$, then the matrix equation can be obtained as follows:

$$
\left[\begin{array}{ccc}
N_{x} k^{2}+\omega^{2} \rho A & 0 & \kappa G A k \\
0 & E I k^{2}+\omega^{2} \rho I & \kappa G A+\omega^{2} \rho I \\
k & -1 & -1
\end{array}\right]\left\{\begin{array}{l}
C \\
D \\
Z
\end{array}\right\}=\left\{\begin{array}{l}
0 \\
0 \\
0
\end{array}\right\} .
$$

If equation (9) has a nonzero solution, then the determinant of the coefficient matrix at the left side must be 0 , which can be written as follows:

$$
\begin{aligned}
& E I\left(\kappa G A+N_{x}\right) k^{4}+\left(-N_{x} \kappa G A+\omega^{2} \rho A E I+\omega^{2} \rho I \kappa G A\right) k^{2} \\
& -\omega^{2} \rho A \kappa G A=0 .
\end{aligned}
$$

By solving equation (10), the dispersion relation of the Timoshenko beam can be modified as follows:

$$
k_{1,2,3,4}= \pm \sqrt{\frac{-\beta \pm \sqrt{\beta^{2}-4 \alpha \gamma}}{2 \alpha}},
$$

where $\alpha=E I\left(\kappa G A+N_{x}\right), \quad \beta=-N_{x} \kappa G A+\omega^{2} \rho A E I+\omega^{2}$ $\rho I \kappa G A$, and $\gamma=-\omega^{2} \rho A \kappa G A$.

2.2. A Numerical Example. After the derivation of the above beam theory, the relationship and difference among the modified Timoshenko beam, Euler-Bernoulli beam, and Timoshenko beam theory are further discussed with a numerical example.

For a continuous uniform section of the beam structure without considering its length, its material parameters are assumed as follows: the elastic modulus is $E=200 \mathrm{GPa}$ and Poisson's ratio is $\mu=0.3$. The section shear deformation coefficient calculated by equation (4) is $\kappa=0.86$. The shear modulus calculated by equation (5) is $G=76.92 \mathrm{GPa}$, and the density is $\rho=7800 \mathrm{~kg} / \mathrm{m}^{3}$. The geometric parameters are as follows: the cross section is circular, its section area is $A=0.005 \mathrm{~m}^{2}$, and cross section moment of inertia is $I_{z z}=2 \times 10^{-6} \mathrm{~m}^{4}$. Suppose the initial tension applied to the beam is $N_{x}=600 \mathrm{MPa} \times 0.005 \mathrm{~m}^{2}=3000 \mathrm{kN}$.

Figure 2 shows the relation between wavenumber solutions and the frequency of the three-beam elements, where the real part is the near-field wave and the imaginary part is the traveling wave. For the low-frequency, the theories dispersion relation among the three-beam theories is very small and almost identical. However, at higher frequencies, the near-field wavenumber solution of the Euler-Bernoulli beam has an infinite increasing trend, which is obviously caused by ignoring the shear deformation and bending stiffness. For the cutoff frequency of the Timoshenko beam, the essence is that only the bending stiffness generated by bending deformation is considered so that the frequency of the fourth power exists in the wavenumber solution. While the rotational inertia caused by shear deformation is considered in the modified Timoshenko beam, the fourth power of frequency in the wavenumber solution is canceled out; thus, the cutoff frequency is avoided [21].

\section{Spectral Elements Based on the Modified Timoshenko Beam}

3.1. The Theory of the Spectral Element. Doyle [18] and Lee et al. [19] proposed a spectral element method to analyze the dynamic response of a continuous mass system, which overcomes the limitation of the finite element method to divide a large number of elements and greatly increase the calculation amount. However, based on the Euler-Bernoulli beam, Zhang [13] deduced the cable spectral element of Timoshenko and increased its applicability. However, as described in Section 1, the theory of the Timoshenko beam has issues. On this basis, this paper used the wavenumber solution of the modified Timoshenko beam theory to replace the solution of reference 13 based on the Timoshenko beam theory and obtained a new wave spectrum element.

3.2. A Numerical Example. For a continuous uniform beam with a length of $10 \mathrm{~m}$ at both ends, its material parameters are assumed as follows: elastic modulus is $E=200 \mathrm{GPa}$, Poisson's ratio is $\mu=0.3$, the section shear deformation 


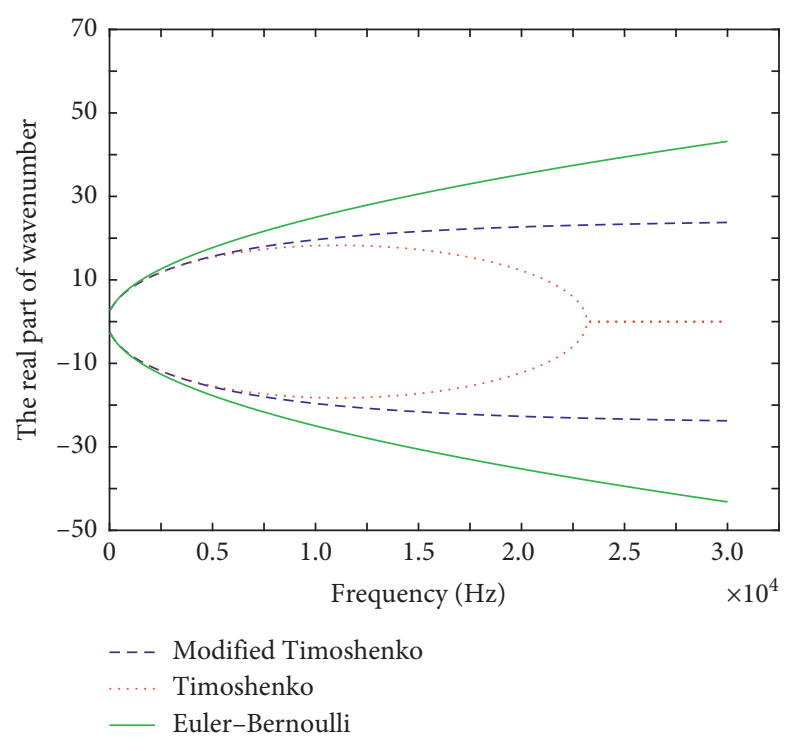

(a)

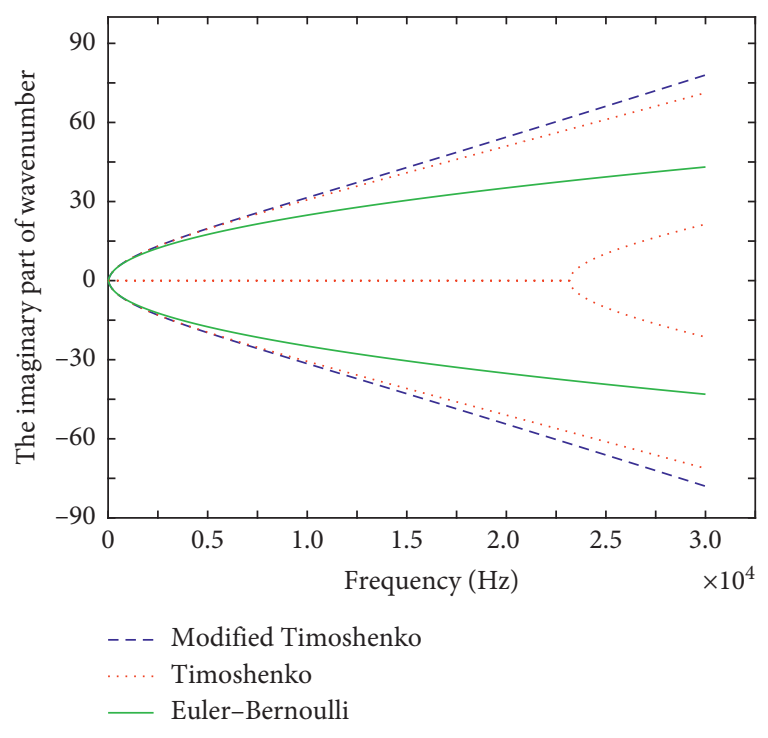

(b)

Figure 2: Wavenumber frequency diagram corresponding to (a) the real part of wavenumber; (b) the imaginary part of the wavenumber.

coefficient calculated by equation (4) is $\kappa=0.86$, the shear modulus is $G=76.92 \mathrm{GPa}$, and the density is $\rho=7800 \mathrm{~kg} / \mathrm{m}^{3}$. The geometric parameters are as follows: the cross section is circular, the radius is $0.04 \mathrm{~m}$, section area is $A=0.005 \mathrm{~m}^{2}$, and the cross-sectional moment of inertia is $I_{z z}=2 \times 10^{-6} \mathrm{~m}^{4}$.

The location is selected at $x=4 \mathrm{~m}$. The method of excitation is by hammering; the signal of the hammer force is a triangular pulse, its amplitude is $F=500 \mathrm{~N}$, the duration of acting is $t=0.01 \mathrm{~s}$, the sampling frequency is $f_{s}=400 \mathrm{~Hz}$, and the sampling point is $N=2^{12}=4096$. In Figures $3-5$, the Fourier spectrum of the excitation force has values in the frequency band of $0,100 \mathrm{~Hz}$, indicating that this hammering can fully stimulate all components in this frequency band.

Since the cross section of the beam is uniform, the sag can be ignored temporarily, and it can be solved through two spectral elements. As shown in Figure 5, for the convenience of observation, the vertical coordinate is taken as the logarithm of the displacement response. In addition, there are 10 maxima in this frequency band, indicating that 10 natural frequencies are located in this frequency band. The abscissa corresponding to the maximum represents the magnitude of the natural frequency. When the frequency is swept near the cells of a certain natural frequency or dichotomy is used, more accurate results of this natural frequency can be obtained.

From Figure 6, as the elements become finer, the traditional finite element model converges to the same result as the spectral element model. Obviously, the spectral element model converges faster. It can be seen from the figure that the accuracy of the 2-element analysis in the spectral element model is comparable to that of the 200-element analysis in the traditional finite element method. Because of the limitations in the number of degrees of freedom, the traditional finite element analysis cannot obtain the natural vibration frequency beyond the number of partition elements. In contrast, the spectral elements have an infinite number of degrees of freedom in space, although dividing into only 2 elements, it can obtain the infinite order natural frequency of vibration, and the error is less than $1 \%$.

\section{Wave Component Decomposition of the Cable Dynamic Response}

4.1. The Theory of Wave Components. In Section 1, the analytical solution of the transverse free vibration in the frequency domain of the cable without considering the sag is given as follows (the later wavenumber solution depends on the modified Timoshenko beam theory):

$$
Y(x, \omega)=C_{1} \exp \left(k_{1} x\right)+C_{2} \exp \left(k_{2} x\right)+C_{3} \exp \left(k_{3} x\right)+C_{4} \exp \left(k_{4} x\right) .
$$

The transverse free vibration of the cable in the frequency domain is superimposed by $\exp \left(k_{2} x\right), \exp \left(k_{2} x\right)$, $\exp \left(k_{3} x\right)$, and $\exp \left(k_{4} x\right)$. In the following text, the above four-wave components are specified as follows:

$C_{1}(\omega) \exp \left(k_{1} x\right)\left[\operatorname{Re}\left(k_{1}\right)<0, \operatorname{Im}\left(k_{1}\right)=0\right]$ is the nearfield wave, which decays along the $x$ positive direction $C_{2}(\omega) \exp \left(k_{2} x\right)\left[\operatorname{Re}\left(k_{2}\right)<0, \operatorname{Im}\left(k_{2}\right)=0\right]$ is the nearfield wave, which decays along the $x$ negative direction $C_{3}(\omega) \exp \left(k_{3} x\right)\left[\operatorname{Re}\left(k_{3}\right)=0, \operatorname{Im}\left(k_{3}\right)<0\right]$ is the traveling wave, which decays along the $x$ positive direction $C_{4}(\omega) \exp \left(k_{4} x\right)\left[\operatorname{Re}\left(k_{4}\right)=0, \operatorname{Im}\left(k_{4}\right)<0\right]$ is the traveling wave, which decays along the $x$ negative direction

Suppose both ends of the cable are fixed constraints. Thus, the displacement and rotation angle of the left end is 0 and that of the right end is 0 , where the boundary conditions can be expressed by equation (13). The matrix equation can be obtained by directly introducing equation (13) into equation (12), as shown in the following: 


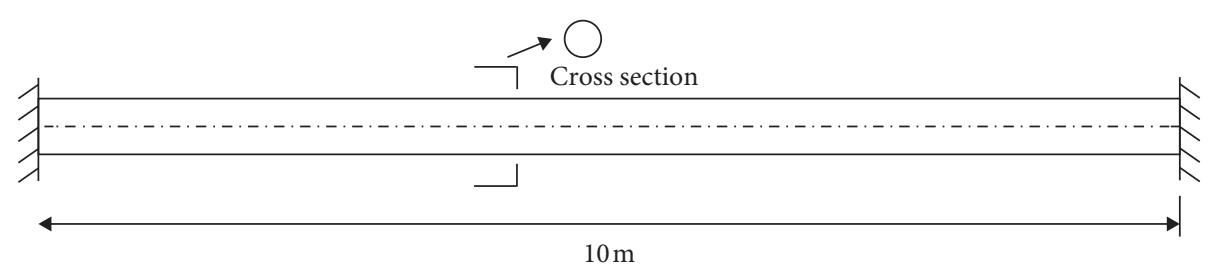

FIgURE 3: Schematic diagram of the beam structure.

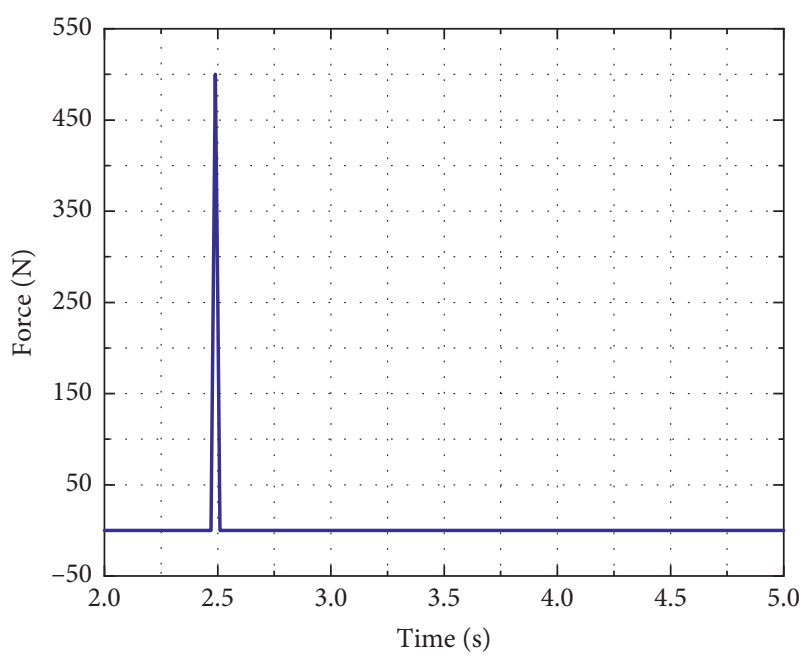

(a)

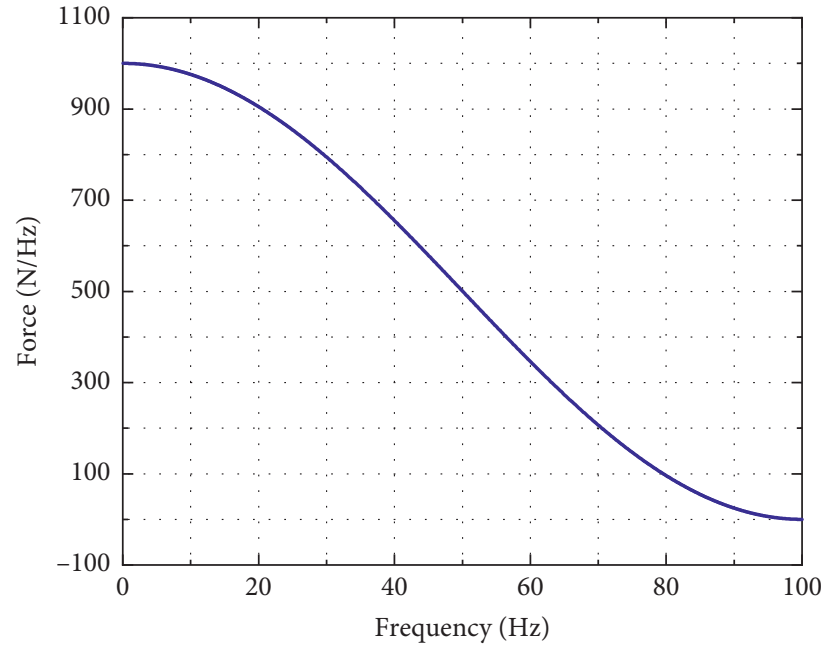

(b)

FIgURE 4: Frequency response of the load.

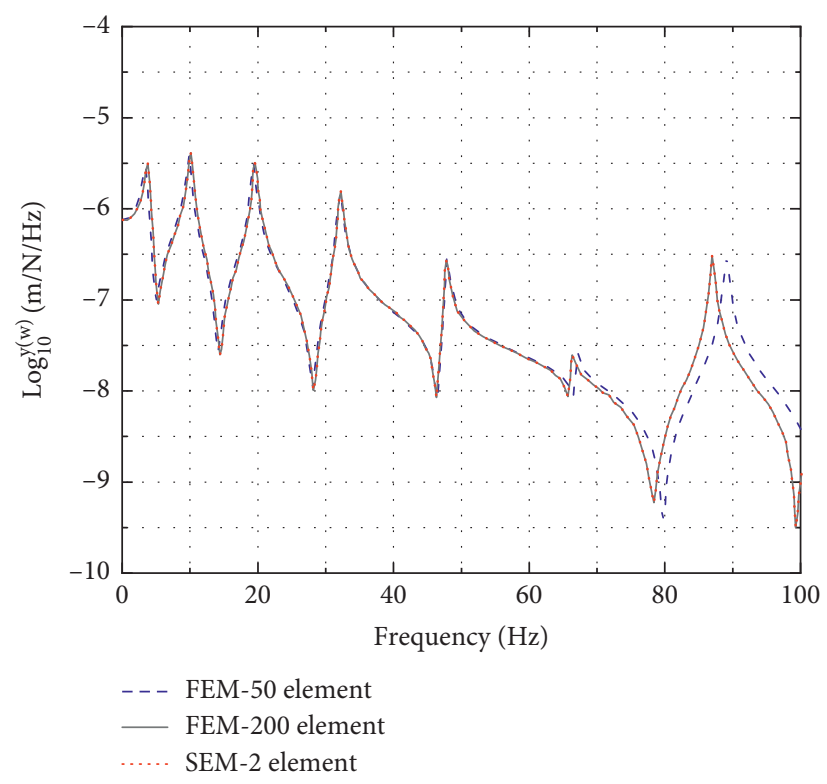

FIgURE 5: Frequency response function diagram. 


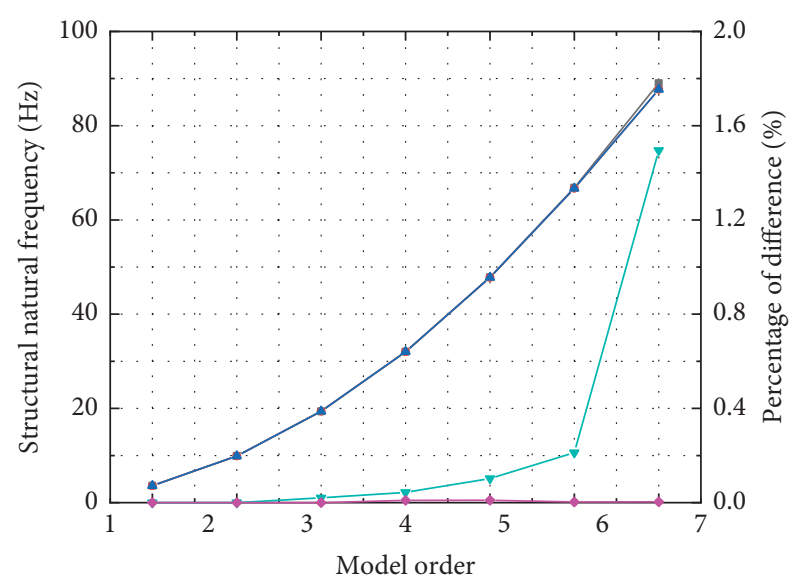

$\longrightarrow$ (a) Finite element $(n=50)$

$\longrightarrow$ (b) Finite element $(n=200)$

$\rightarrow$ (c) Spectrum element $(n=2)$

$\rightarrow$ Difference between (a) and (c)

$\rightarrow$ Difference between (b) and (c)

FIgURE 6: Structural natural frequency and comparison.

$$
\begin{gathered}
y_{(0)}=0, \\
y_{(0)}^{\prime}=0, \\
y_{(l)}=0, \\
y_{(l)}^{\prime}=0, \\
H \cdot C=0,
\end{gathered}
$$

where

$$
\begin{gathered}
C=\left\{\begin{array}{llll}
C_{1} & C_{2} & C_{3} & C_{4}
\end{array}\right\}^{\mathrm{T}}, \\
H=\left\{\begin{array}{cccc}
1 & 1 & 1 & 1 \\
k_{1} & k_{2} & k_{3} & k_{4} \\
\exp \left(k_{1} L\right) & \exp \left(k_{2} L\right) & \exp \left(k_{3} L\right) & \exp \left(k_{4} L\right) \\
k_{1} \exp \left(k_{1} L\right) & k_{2} \exp \left(k_{2} L\right) & k_{3} \exp \left(k_{3} L\right) & k_{4} \exp \left(k_{1} L\right)
\end{array}\right\} .
\end{gathered}
$$

Similarly, if the cable displacement has a nonzero solution, then the determinant of the coefficient matrix must be 0 , which can be written as $\omega=\left\{\omega_{n} \mid H\left(\omega_{n}\right)=0\right\}$. Thus, the modal decomposition expression of the structure can be obtained as follows:

$$
\begin{aligned}
\omega & =\left\{\omega_{1}, \omega_{2}, \ldots, \omega_{n}\right\}^{\mathrm{T}}, \\
Y\left(x, \omega_{n}\right) & =\sum_{i=1}^{4} C_{i}\left(\omega_{n}\right) \exp \left(k_{i} x\right) .
\end{aligned}
$$

4.2. A Numerical Example. In Figure 7, for a continuous uniform beam with a length of $10 \mathrm{~m}$ at both ends, its material parameters including the elasticity modulus E, Poisson's ratio $\mu$, the section shear deformation coefficient $\kappa$, the shear modulus $G$, density $\rho$, the section area $A$, and cross-sectional moment of inertia $I_{z z}$ are the same as the numerical example in Section 2.2. Substituting each parameter into equation (16), the value of $\operatorname{det}(H)$ is obtained in the frequency range of $0 \sim 1000 \mathrm{~Hz}$ in Figure 8, and each minimum point corresponds to each natural frequency of the beam.

Equation (12) indicates that the response of the cable at each frequency point is superimposed by four kinds of waves. To further explore the properties of each wave, two groups are divided as follows:

$$
Y(x, \omega)=C_{1} \exp \left(k_{1} x\right)+C_{2} \exp \left(k_{2} x\right),
$$

which is the near-field wave component.

$$
Y(x, \omega)=C_{3} \exp \left(k_{3} x\right)+C_{4} \exp \left(k_{4} x\right),
$$

which is the traveling wave component.

In Figure 8 , the $3^{\text {rd }}$ order natural frequency valued at 19.387 is selected from the low-frequency band. In the same way, the $25^{\text {th }}$ order natural frequency value of 982.463 is selected from the high-frequency band. At the above frequencies, the basic solution system of equation (12) is obtained, and then the near-field wave and traveling wave are obtained according to equations (18) and (19). The results are shown in Figure 9. Near-field waves only exist near the boundary and decay exponentially. With increasing frequency, the decay speed is faster.

\section{Cable Force Identification Method Based on a Substructure Bending Wave}

5.1. The Theory of the Identification Method. From the derivation of the formula in Section 2, the dynamic response at any position in the cable can be written as the superposition of four-wave components at each frequency point. The characteristics of the four-wave components are studied by the numerical example in Section 3, where the near-field wave decays rapidly and generally. In addition, this component only exists in a relatively small range at the consolidation point, which is neglected in the high-frequency band $[22,23]$. Therefore, the vibration response of the cable can be written as follows:

$$
Y(x, \omega)=C_{3} \exp \left(k_{3} x\right)+C_{4} \exp \left(k_{4} x\right) .
$$

Therefore, a certain section of the cable can be selected as the research object and the response of any point in the subcable segment still meets equation (20). Different from the conventional solution, the dynamic response of the internal measuring points of the cable is solved in this paper, so the complex boundary condition is avoided [24]. Now suppose $M$ measuring points are arranged on the subcable segment:

$$
X=\left\{x_{1}, x_{2}, \ldots, x_{M}\right\} .
$$

To avoid the spectrum leakage problem caused by the Fourier transform, Doyle [18] proposed replacing the Fourier transform with the Laplace transform and achieved a very good result. The dynamic response results of each measurement point are converted into the Laplace transform and are transformed into the frequency domain: 


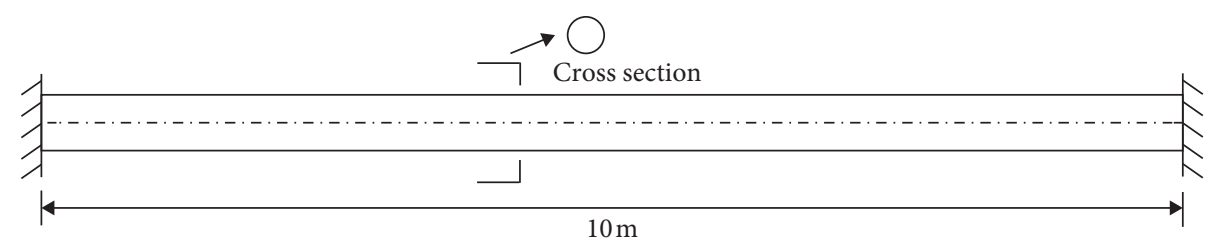

Figure 7: Structure diagram.

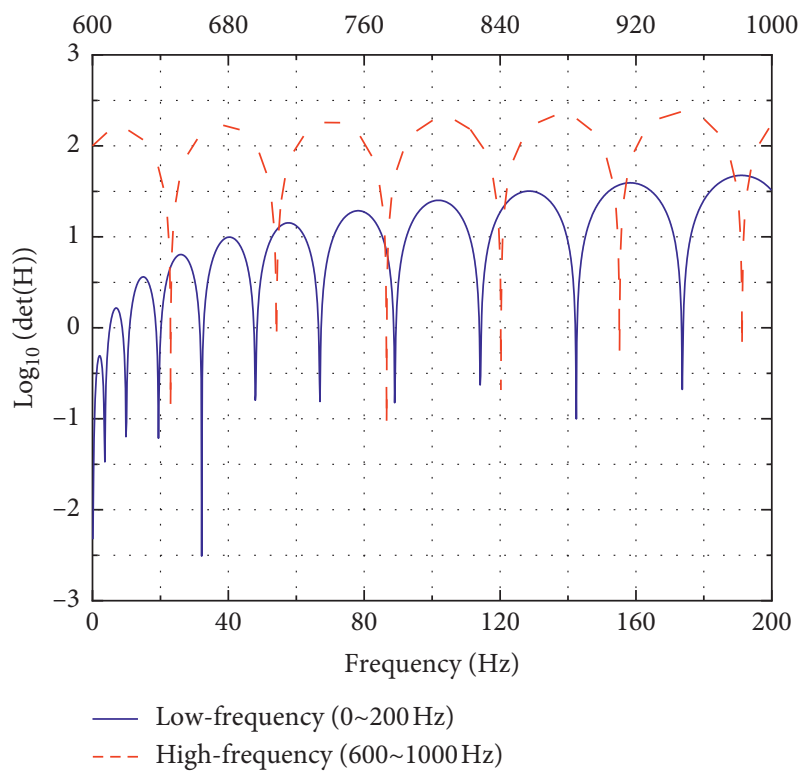

Figure 8: $\operatorname{Det}(H)$ distribution.

$$
\widehat{Y}_{\mathrm{ob}}=\left[\begin{array}{cccc}
\hat{Y}_{\mathrm{ob}}\left(x_{1}, s_{1}\right) & \hat{Y}_{\mathrm{ob}}\left(x_{1}, s_{2}\right) & \ldots & \hat{Y}_{\mathrm{ob}}\left(x_{1}, s_{n}\right) \\
\hat{Y}_{\mathrm{ob}}\left(x_{2}, s_{1}\right) & \hat{Y}_{\mathrm{ob}}\left(x_{2}, s_{2}\right) & \ldots & \hat{Y}_{\mathrm{ob}}\left(x_{2}, s_{n}\right) \\
\vdots & \vdots & \ddots & \vdots \\
\hat{Y}_{\mathrm{ob}}\left(x_{M}, s_{1}\right) & \hat{Y}_{\mathrm{ob}}\left(x_{M}, s_{2}\right) & \ldots & \hat{Y}_{\mathrm{ob}}\left(x_{M}, s_{n}\right)
\end{array}\right],
$$

where $s_{i}$ is the complex frequency and $\hat{Y}_{\mathrm{ob}} \in C^{m \times n}$ is the observation matrix. The dynamic response of each measurement point should meet equation (20), and the matrix equation can be obtained as follows:

$$
D\left(s_{j}\right) \cdot C\left(s_{j}\right)=\widehat{Y}_{\mathrm{ob}}\left(s_{j}\right),
$$

where

$$
D\left(s_{j}\right)=\left[\begin{array}{cc}
\exp \left(k_{3}\left(s_{j}\right) x_{1}\right) & \exp \left(k_{4}\left(s_{j}\right) x_{1}\right) \\
\vdots & \vdots \\
\exp \left(k_{3}\left(s_{j}\right) x_{n}\right) & \exp \left(k_{4}\left(s_{j}\right) x_{n}\right)
\end{array}\right] .
$$

This matrix is the structural characteristic matrix, depending on the position of the measuring points and the cable parameters:

$$
C\left(s_{j}\right)=\left\{C_{3}\left(s_{j}\right) C_{4}\left(s_{j}\right)\right\} .
$$

This matrix is the coefficient matrix, depending on the structural characteristics and the external excitation:

$$
\widehat{Y}_{\mathrm{ob}}\left(s_{j}\right)=\left\{\hat{Y}_{\mathrm{ob}}\left(x, s_{j}\right) \hat{Y}_{\mathrm{ob}}\left(x, s_{j}\right) \ldots \hat{Y}_{\mathrm{ob}}\left(x, s_{j}\right)\right\} .
$$

This vector is the observation vector, located in the $j$ column of equation (22). If the parameters of the cable, the arrangement of measurement points, and the response results of each measurement point have been obtained, then the wave component coefficients can be solved by the least square method $[13,14]$ :

$$
C\left(s_{j}\right)=\left[D^{T} D\right]^{-1} \cdot D^{T} \widehat{Y}_{\mathrm{ob}} .
$$

If $n<2$ and $C\left(s_{j}\right)$ have innumerable solutions, then parameter identification is impossible. If $n=2$ and $C\left(s_{j}\right)$ has only a unique solution, then the parameter correction is still not possible. If $n>2$ and $C\left(s_{j}\right)$ has a least squares solution, then the fitting residuals are as follows:

$$
\varepsilon=\left\{D\left(s_{j}\right)\left[D^{T}\left(s_{j}\right) D\left(s_{j}\right)\right]^{-1} D^{T}\left(s_{j}\right)-I\right\} \hat{Y}_{\mathrm{ob}}\left(s_{j}\right) .
$$

If the parameters of the structural characteristics of the matrix completely have correct values and the observations have no noise interference, then the fitting residual error is 0 . In fact, the cable force as the object to identify is unable to be correctly estimated, so the cable force value should be modified. Then the standard of cable force identification can be obtained by reaching the minimum of the standardized fitting residual:

$$
P=\{N, E I\}=\min \frac{\|\varepsilon\|}{\left\|D\left(s_{j}\right)\left[D^{T}\left(s_{j}\right) D\left(s_{j}\right)\right]^{-1} D^{T}\left(s_{j}\right) \widehat{Y}_{\mathrm{ob}}\left(s_{j}\right)\right\|\left\|\widehat{Y}_{\mathrm{ob}}\left(s_{j}\right)\right\|} .
$$

5.2. A Numerical Example for Cable Force Identification. This section takes the cable model as an example to verify the cable force identification method of the subcable segment. In Figure 10 , the length of the cable is $L=100 \mathrm{~m}$, and the gradient is $\sin \alpha=0.6$; its material parameters, including the elasticity modulus $E$, Poisson's ratio $\mu$, the section shear deformation coefficient $\kappa$, the shear modulus $G$, the density $\rho$, section area $A$, and the cross-sectional moment of inertia $I_{z z}$, are the same as the numerical example in Section 2.2. In this paper, a $1.0 \mathrm{~m}$ hard cable clamp is set at both ends of the cable, and its bending stiffness is 20 times that of the cable, approximately simulating the influence of the tower beam on them. The measuring points are arranged at a position 


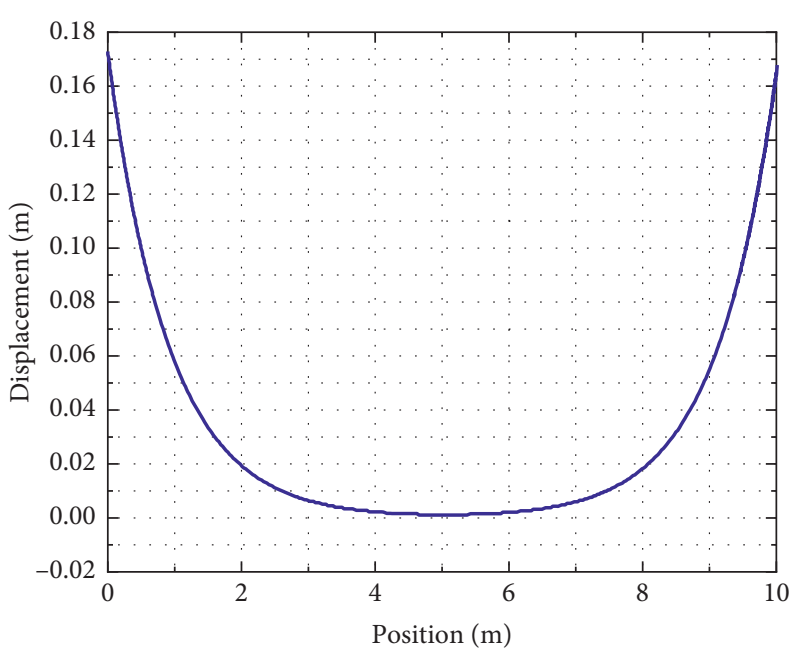

— Near wave

(a)

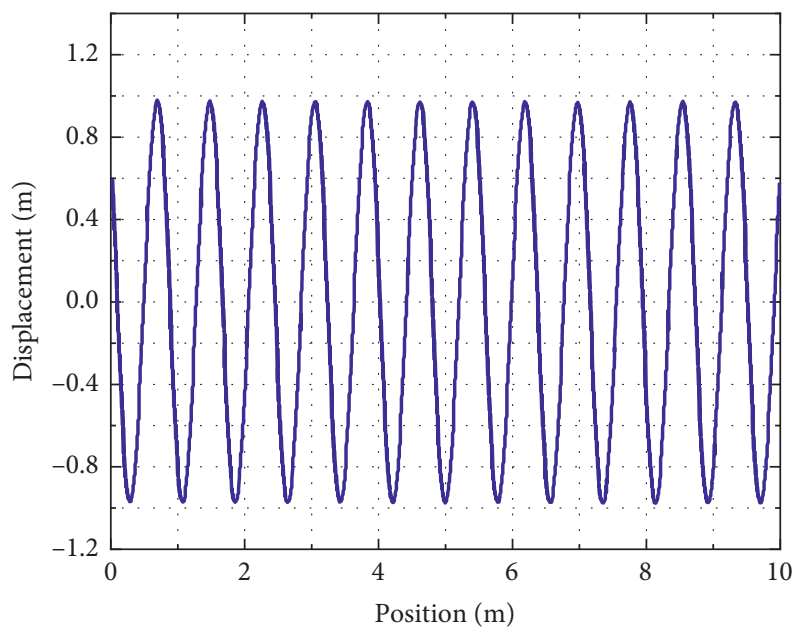

- Propagation wave

(c)

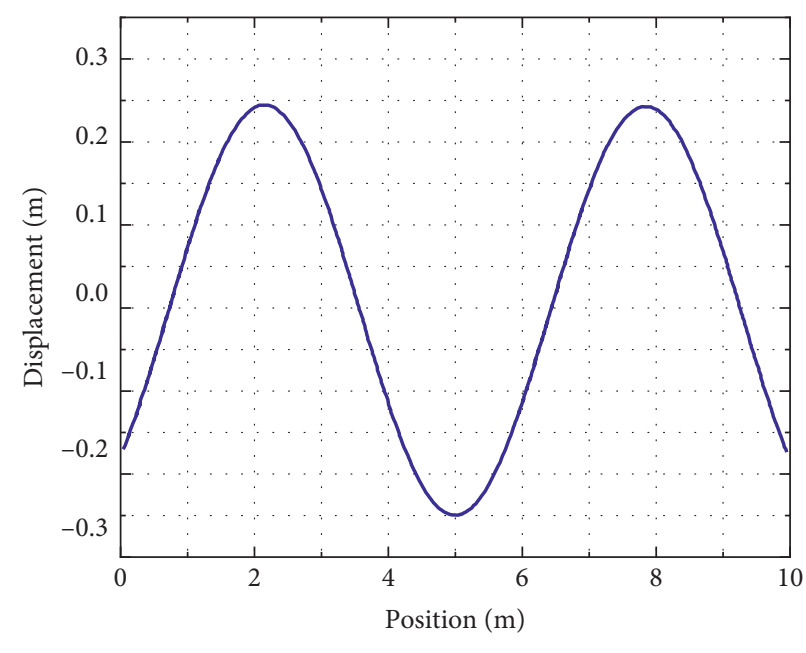

— Propagation wave

(b)

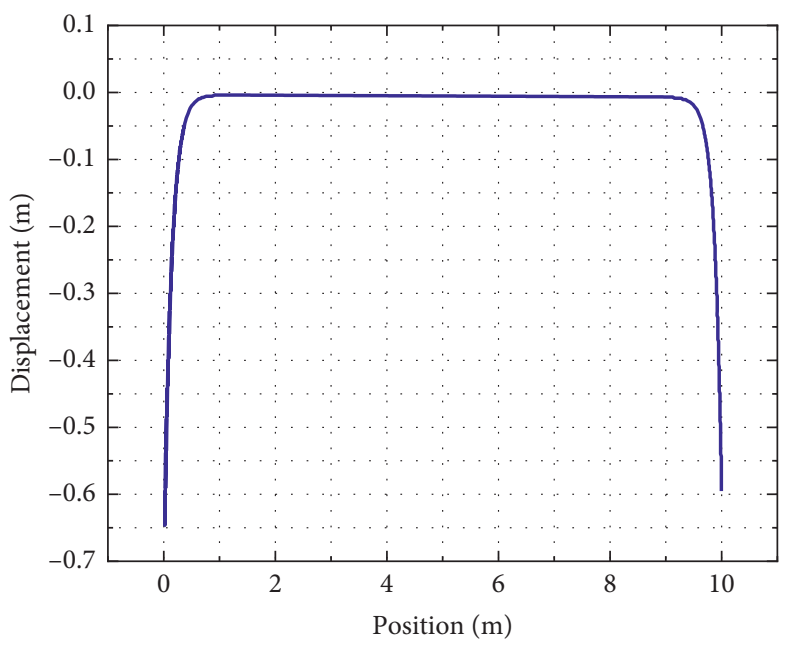

Near wave

(d)

FiguRe 9: Wave component diagram, (a) near wave component (exp $\left.\left(k_{1} x\right)\right)$, (b) traveling wave component $\left(\exp \left(k_{3} x\right)\right)$, (c) near wave component $\left(\exp \left(k_{2} x\right)\right)$, and $(d)$ traveling wave component $\left(\exp \left(k_{4} x\right)\right)$.

$2.0 \mathrm{~m}$ away from the cable clip, and three measuring points are arranged continuously at an interval of $1.0 \mathrm{~m}$.

The cable dynamic model is established by spectral element programming. The initial tension is set as $3000 \mathrm{kN}$ and the drive point is set at $1 \mathrm{~m}$ outside the cable clamp. It is assumed that the hammer strike force is the same as that used in Section 3, but the sampling frequency is $100 \mathrm{~Hz}$, and the sampling points are $N=2^{12}=4096$. The time domain diagram of the excitation and Fourier coefficient spectrum is shown in Figure 4.

In Figure 11, the obtained time domain dynamic responses of the three measuring points were transformed into the frequency domain by the Laplace transform. Then, the observation matrix of the measuring points was assembled by equation (22), and the various parameters of the cable are brought into equation (24). The position of the first measuring point is 0 points, and the $x$-axis is established along the cable direction to form the structural characteristic matrix.

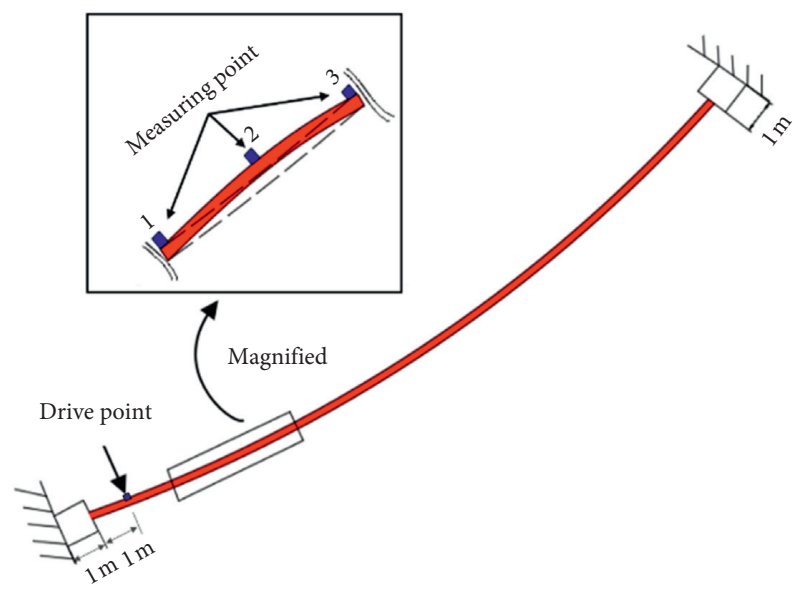

Figure 10: Cable diagram. 


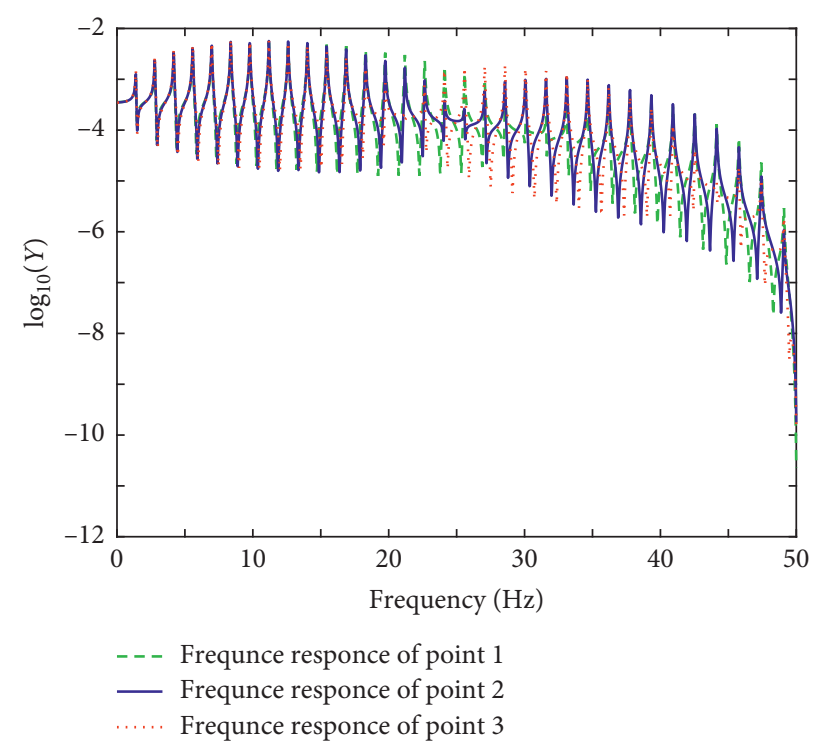

FIGURE 11: Frequency domain response diagram.

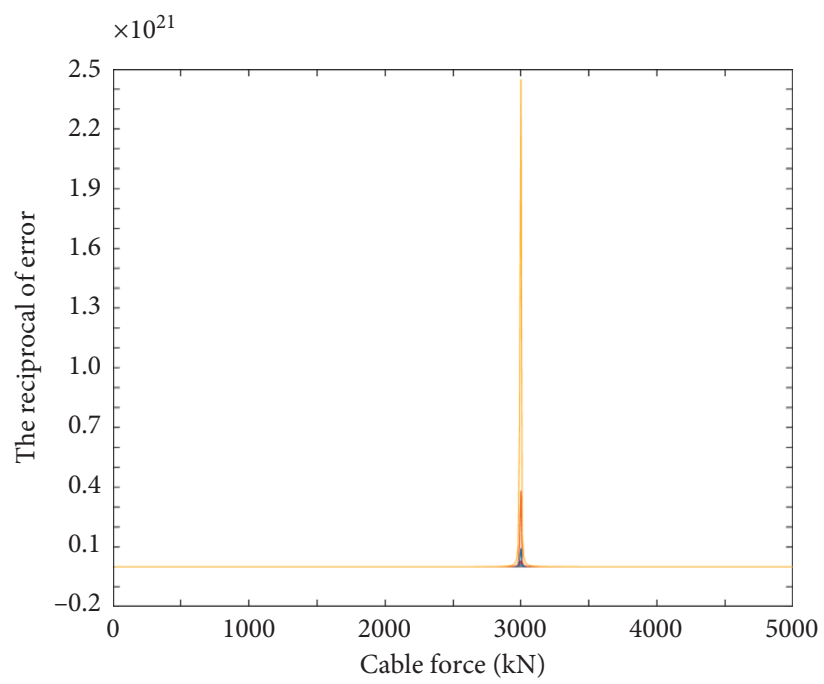

FIgURE 12: Schematic diagram of the cable force identification.

The fitting residual at each frequency point is calculated to identify the cable force by equation (29). The fitting residuals of each cable force value are drawn to facilitate observation. Figure 12 shows the fitting residuals of the cable force value corresponding to different frequency points. In Figure 12, the identification value is $3026.8 \mathrm{kN}$ with an error of only $0.9 \%$, which has quite a high accuracy.

\section{Analysis of the Influencing Factors of Cable Force Identification}

6.1. External Load Mode. Compared with the hammering load in Section 4, this section discusses various load modes and provides the cable force identification accuracy. (i) Case 1: the external force is simulated with a rectangular pulse signal, supposing the amplitude is $500 \mathrm{~N}$, the duration of action is $t=0.2 \mathrm{~s}$, the sampling frequency is $100 \mathrm{~Hz}$, and the sampling points are $N=2^{12}=4096$

(ii) Case 2: The external force is simulated with a halfsine signal, supposing the amplitude is $500 \mathrm{~N}$, the duration of action is $t=3 \mathrm{~s}$, the sampling frequency is $100 \mathrm{~Hz}$, and the sampling points are $N=2^{12}=4096$

(iii) Case 3: The external force is simulated with a random signal, supposing the mean is $500 \mathrm{~N}$, the variance is 0.5 , the duration of action is $40.96 \mathrm{~s}$, the sampling frequency is $100 \mathrm{~Hz}$, and the sampling points are $N=2^{12}=4096$ 


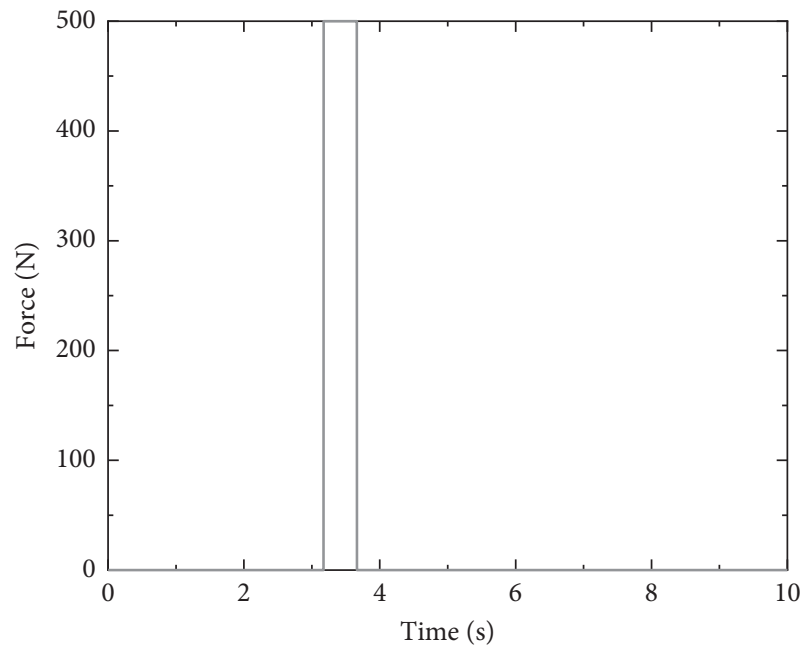

_ The load in time field

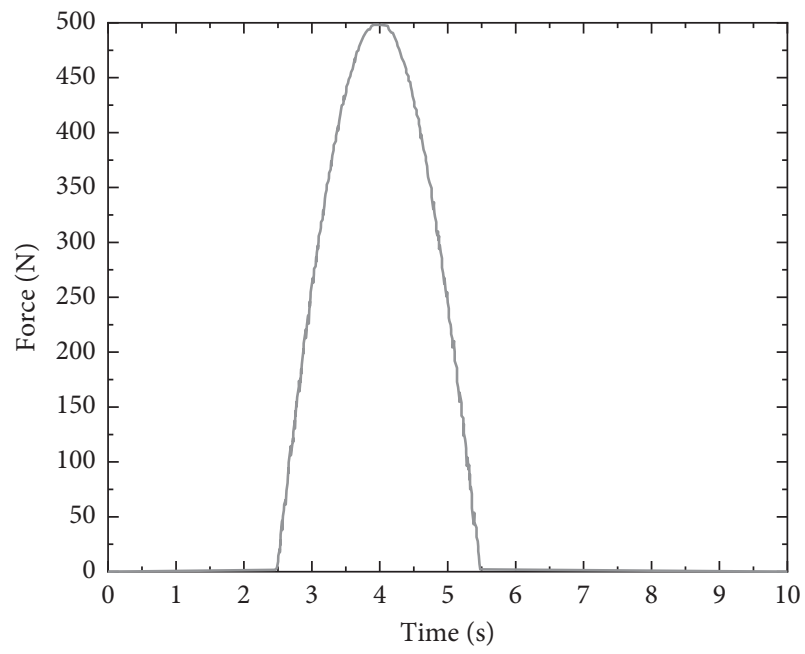

_ The load in time field

(b)

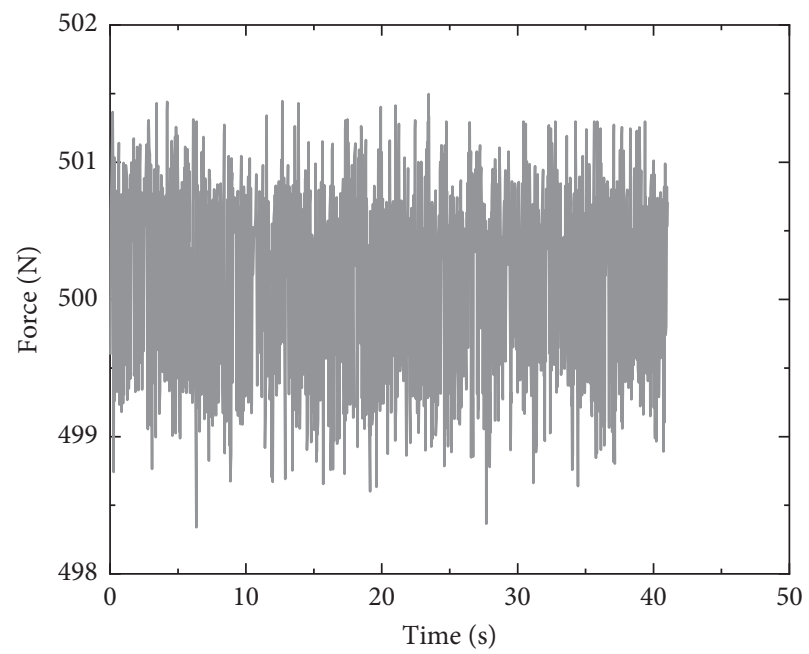

— The load in time field

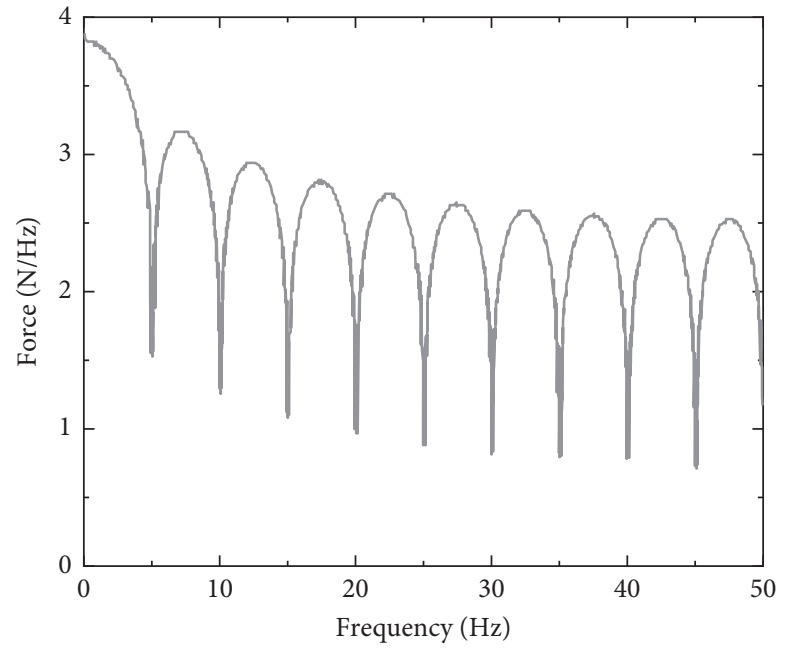

— The load in frequency field

(a)

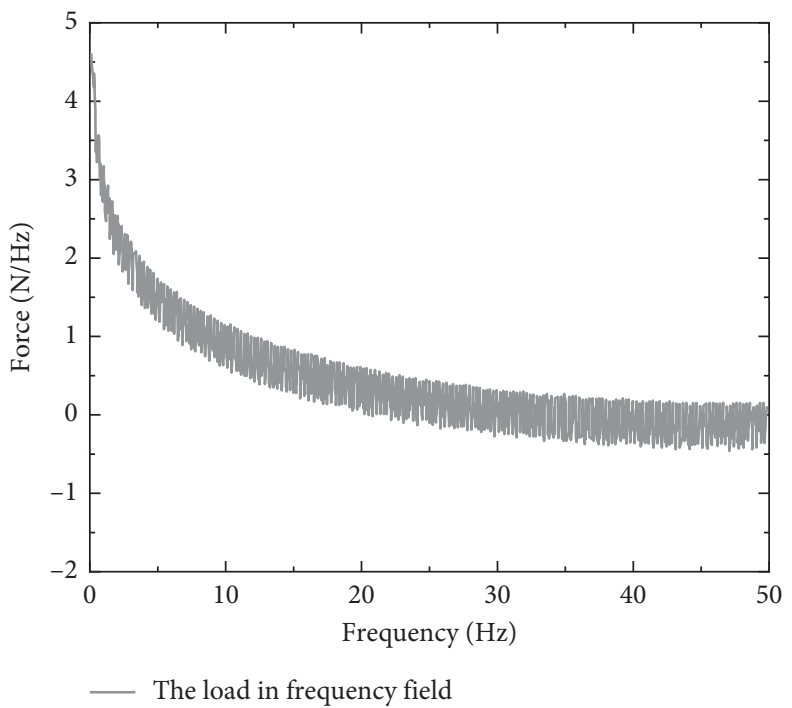

)

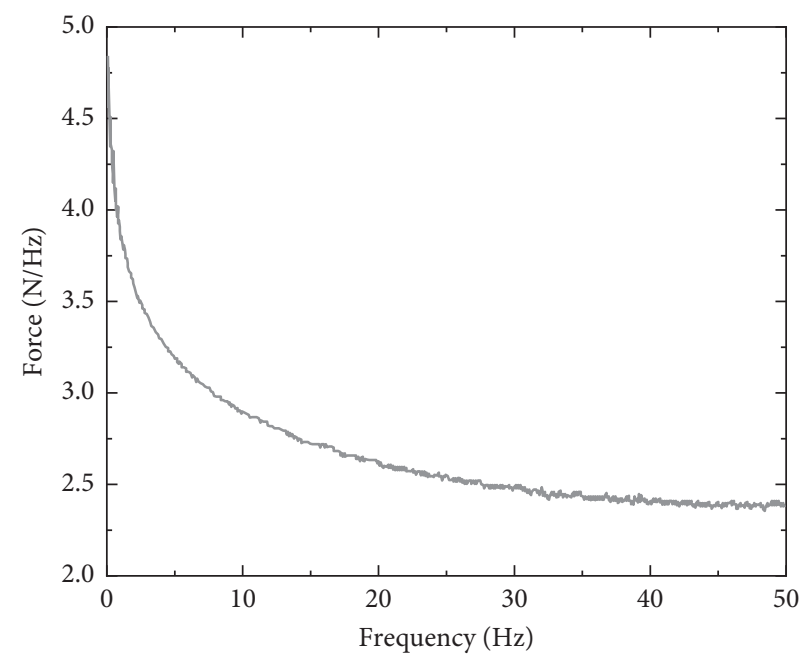

— The load in frequency field

(c)

Figure 13: Force diagram: (a) case 1, (b) case 2, and (c) case 3. 


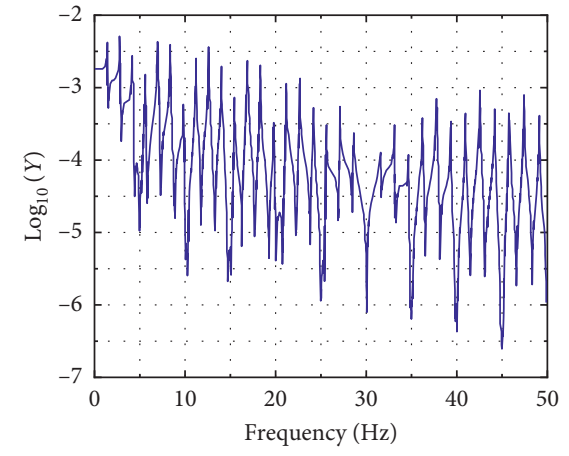

- The frequency response of point 1

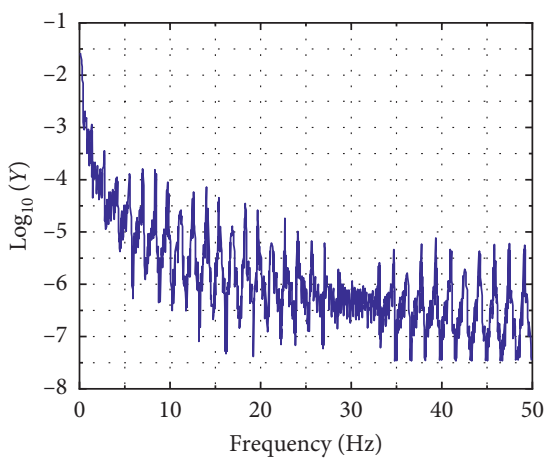

- The frequency response of point 1

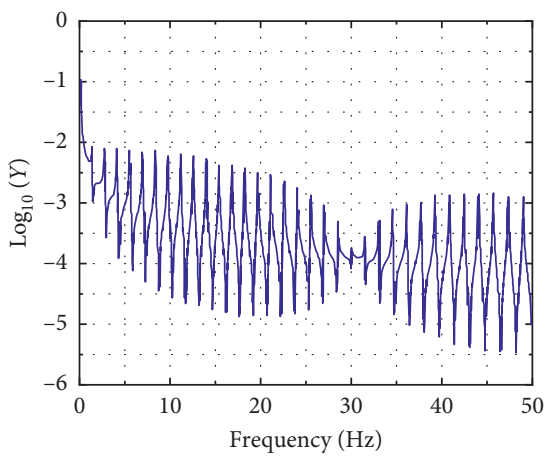

_ The frequency response of point 1

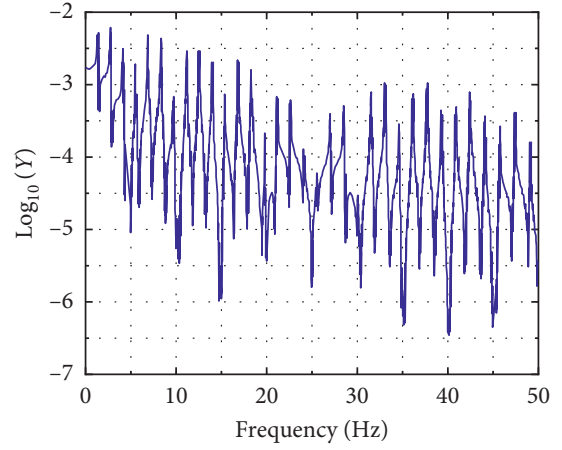

_ The frequency response of point 2

(a)

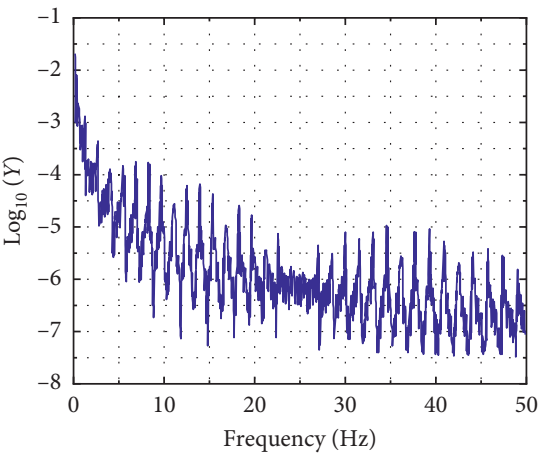

_ The frequency response of point 2

(b)

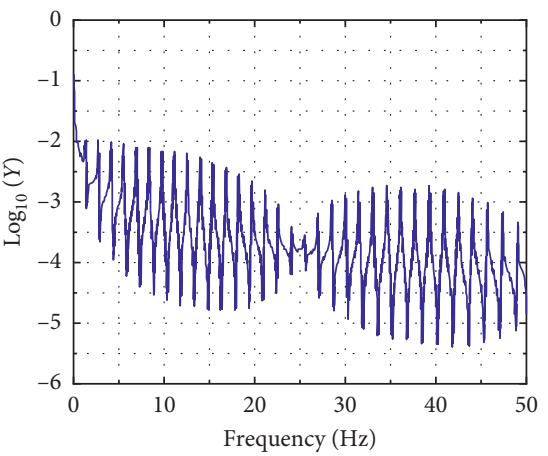

_ The frequency response of point 2

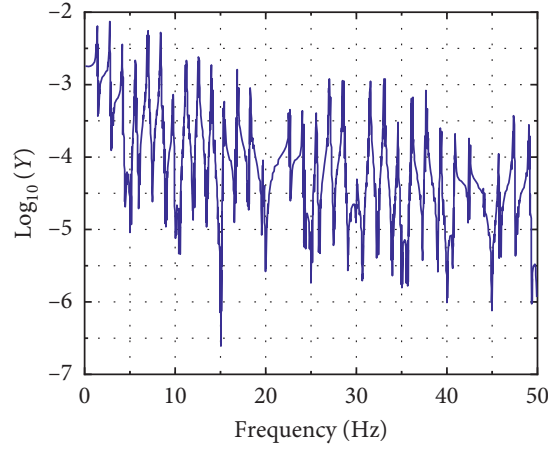

_ The frequency response of point 3

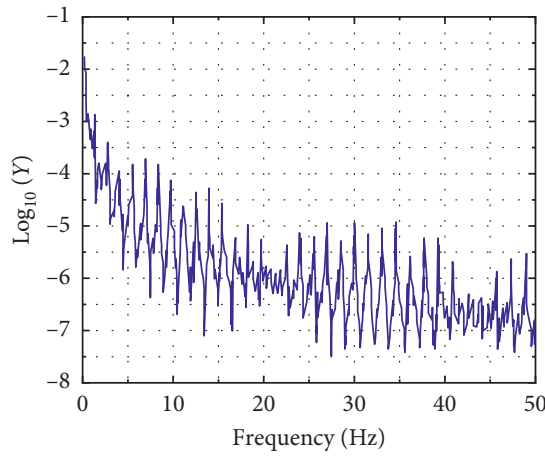

_ The frequency response of point 3

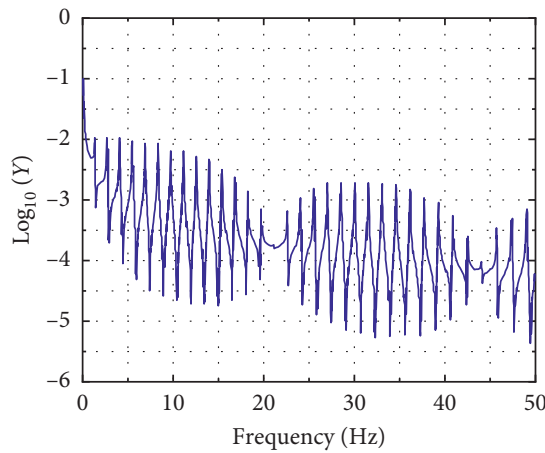

_ The frequency response of point 3

(c)

Figure 14: Frequency domain response of the measuring point under external load models: (a) case 1; (b) case 2; (c) case 3.

The time domain diagram of the excitation and Fourier coefficient spectrum is shown in Figure 13, which can excite all components in the $0,50 \mathrm{~Hz}$ frequency band (except for different load forms, the other cable parameters are consistent with the numerical example in Section 4.2).

The dynamic response frequency domain of the three measuring points obtained by this input load mode is shown in Figure 14. The frequency response of the three obtained points is substituted in the equation of the solution of the fitting residual. To observe clearly, taking the reciprocal is shown in Figure 15. The cable force identification values are $3019.2 \mathrm{kN}, 3024.5 \mathrm{kN}$, and $3017.8 \mathrm{kN}$, and their errors are all less than $1 \%$. Through the above example, cable force identification is independent of the form of the external force and maintains an extremely high accuracy under various force modes.

6.2. Bending Stiffness of the Cable. Both geometric stiffness and physical stiffness exist in the cable. The earliest frequency method deduced the relationship between the frequency and cable force through string theory, without considering the physical stiffness of the cable. Therefore, there is a large error in cable force identification by the dynamic measurement method. Furthermore, considerable studies have confirmed that the bending stiffness of the cable 


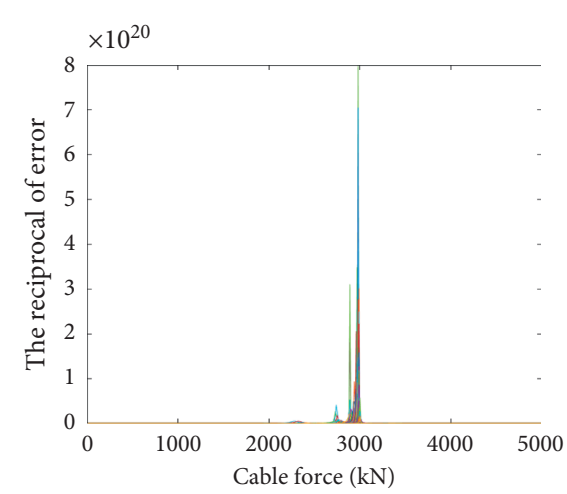

(a)

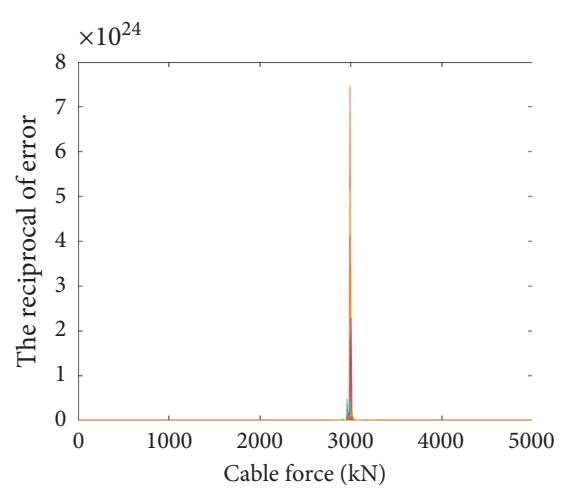

(b)

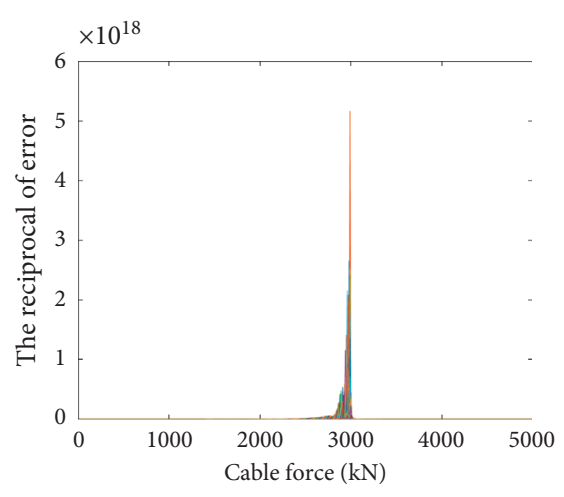

(c)

FIGURE 15: Cable force identification diagram corresponding to the frequency response of (a) point 1; (b) point 2; and (c) point 3.

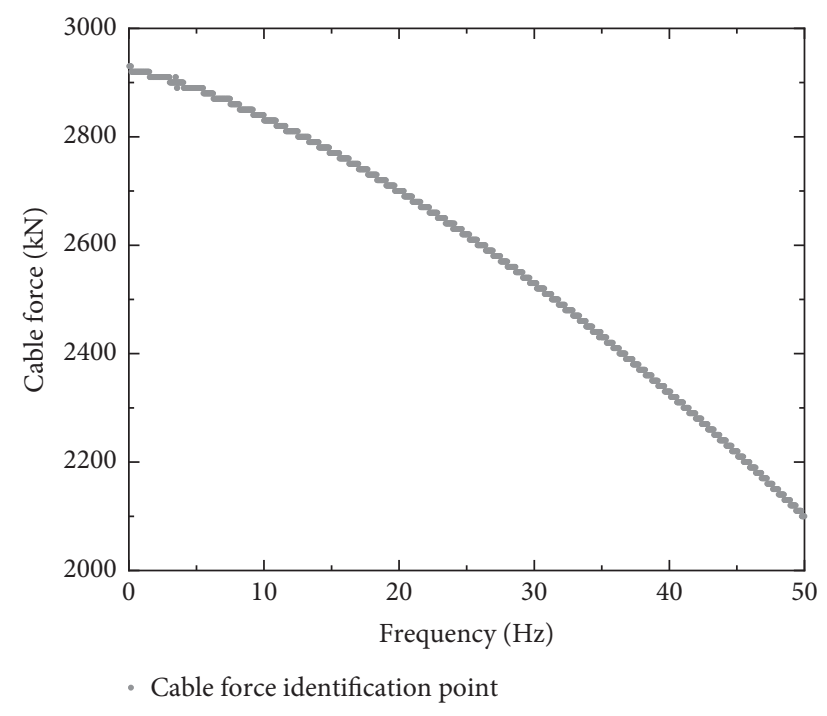

FIgURE 16: Cable force identification of the resulting diagram.

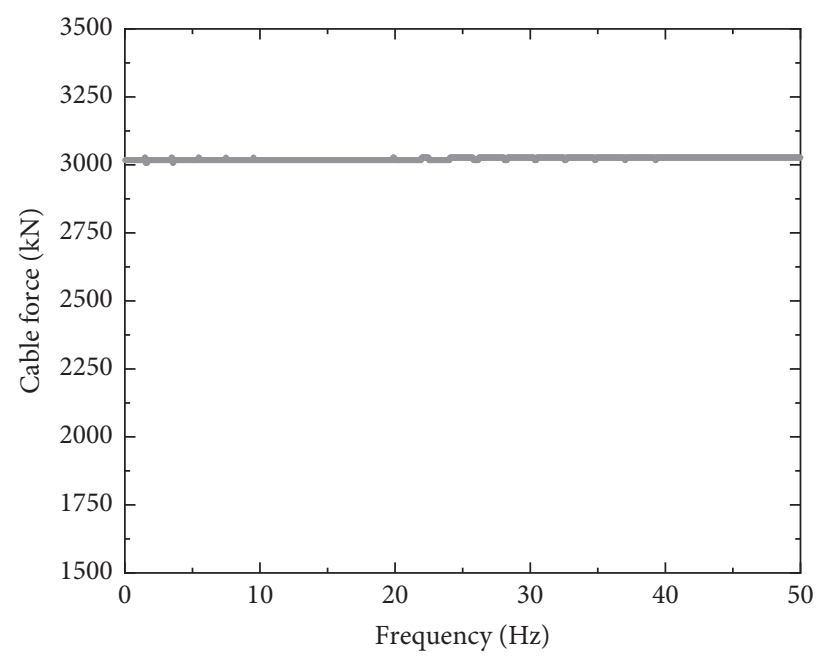

- Cable force identification point

FIGURE 17: Recognition result after updating the bending stiffness. 
must be considered for the identification of the cable force through the dynamic method. However, there is still no exact equation to value the bending stiffness of these special structures $[8,25,26]$.

Shimada, a Japanese scholar, found that the bending stiffness of a cable is usually 0.5 times the calculated bending stiffness [27]. The research of Australian scholar Geier et al. shows that $2 / 3$ of the calculated bending stiffness should be taken [28]. Xie corrected the bending stiffness in his study by minimizing the error between the measured value and the calculated value of the frequency [29] and believed that the bending stiffness of the cable is usually 0.3-0.4 times the calculated bending stiffness. Therefore, accurately using the bending stiffness to identify the cable force still has certain research value. In this paper, multiparameter identification is carried out theoretically in Section 4, but the identification of the cable force and physical stiffness at the same time easily produces incorrect results. In fact, through the theoretical derivation in Section 2, it is not difficult to determine that with increasing frequency, the influence of the cable bending stiffness is also increasing. If the value of the bending stiffness used for cable force identification is greater than the actual stiffness of the cable, then it can be inferred that the identified cable force will decrease with an increase in the frequency point.

In the numerical example in Section 4, some conditions are added as follows: the calculated moment of inertia of the section is $I_{z z}=2 \times 10^{-6} \mathrm{~m}^{4}$ and the actual moment of inertia of the section is $I_{z z}=0.6 \times 10^{-6} \mathrm{~m}^{4}$. Then the actual moment of inertia is substituted into the model to obtain the dynamic response of the cable and the cable force is identified by calculating the moment of inertia.

In Figure 16, the value of the bending stiffness in cable force identification is larger than the actual stiffness, so a line of cable force identification with a negative slope results, which is consistent with the above inference. In fact, only the bending stiffness needs to be modified to identify the correct cable force result, and this can be done as follows:

(1) Taking $\alpha=1$ to calculate the bending stiffness $\alpha$ EI, calculating the cable force at each frequency point, and conducting linear fitting, with slope $\beta$

(2) Taking another value of $0<\alpha<1$ to calculate the sensitivity named $\alpha^{\prime}$ of $\alpha$ to $\beta$

(3) Updating the bending stiffness with $\alpha=\beta-\alpha^{\prime} \beta$

(4) Fitting the cable force with the updated bending stiffness and obtaining the slope $\beta$

(5) Exporting the cable force when $\beta$ is less than the preset value

In Figure 17, the cable force identification results tend to be a horizontal line after several bending stiffness modifications, where $\alpha=0.303$ and is only $1 \%$ different from the theoretical value of 0.3 . The cable force identification result is 3027.6 , with an error of $0.92 \%$, which maintains quite a high accuracy.

\section{Conclusions}

In this paper, the current common methods of cable force identification are summarized, and the theory and application conditions of each method are briefly described. Then, the dispersion relation of the vibration model for the modified Timoshenko beam is derived, and the wave components of the cable are discussed separately. The conclusions are obtained as follows:

(1) A new theory of the cable force identification method using the traveling wave in the cable is proposed. The least square method is used to fit the wave component coefficient, taking the minimum fitting residual as the objective to identify the cable force.

(2) By selecting a substructure of the cable and using the dynamic response of the three measuring points, the cable force of the subsegment of the cable is identified. This method only demands the parameters of the cable section and the relative positions of the three measuring points to identify the cable force.

(3) By analyzing the influence of the bending stiffness on cable force identification and proposing the corresponding solution, the favorable results of cable force identification were obtained with a theoretical deviation of less than $1 \%$.

\section{Data Availability}

The data used to support the findings of this study are available from the corresponding author upon request.

\section{Conflicts of Interest}

The authors declared no potential conflicts of interest with respect to the research, authorship, and/or publication of this article.

\section{Acknowledgments}

This work was financially supported by the CCCC Mega R \& D Project (no. 2019-ZJKJ-07), the National Natural Science Foundation of China (nos. 51708464 and 51708465), and the Fundamental Research Funds for the Central Universities (no. 2682019CX02).

\section{References}

[1] T. Nagayama, S. H. Sim, Y. Miyamori, and B. F. Spencer Jr., "Issues in structural health monitoring employing smart sensors," Smart Structures and Systems, vol. 3, no. 3, pp. 299-320, 2007.

[2] J.-T. Kim, K.-D. Nguyen, and T.-C. Huynh, "Wireless health monitoring of stay cable using piezoelectric strain response and smart skin technique," Smart Structures and Systems, vol. 12, no. 3_4, pp. 381-397, 2013.

[3] M. Y. Guo, Z. H. Chen, H. B. Liu, X. F. Wu, and Y. B. Li, "Cable cable test technology and bending stiffness research progress," Spatial Structure, vol. 22, pp. 34-43, 2016.

[4] S. E. H. A. M. Zarbaf, M. Norouzi, R. Allemang, V. Hunt, A. Helmicki, and C. Venkatesh, "Vibration-based cable condition assessment: a novel application of neural networks," Engineering Structures, vol. 177, pp. 291-305, 2018.

[5] S. E. H. A. M. Zarbaf, M. Norouzi, R. J. Allemang et al., "Ironton-russell bridge: application of vibration-based cable 
tension estimation," Journal of Structural Engineering, vol. 144, no. 6, Article ID 04018066, 2018.

[6] Y. Y. Wang, "Study on vibration characteristics and parameter identification of short cables," Master thesis, Southwest Jiaotong University, Chengdu, China, 2017.

[7] X. W. Ye, C. Z. Dong, and T. Liu, "Force monitoring of steel cables using vision-based sensing technology: methodology and experimental verification," Smart Structures and Systems, vol. 18, no. 3, pp. 585-599, 2016.

[8] B. Vogelaar and M. Golombok, "Quantification and localization of internal pipe damage," Mechanical Systems and Signal Processing, vol. 78, pp. 107-117, 2016.

[9] X. Y. Li, L. X. Wang, S. S. Law, and Z. H. Nie, "Covariance of dynamic strain responses for structural damage detection," Mechanical Systems and Signal Processing, vol. 95, pp. 90-105, 2017.

[10] M. Dehghan and M. Abbaszadeh, "Analysis of the element free Galerkin (EFG) method for solving fractional cable equation with Dirichlet boundary condition," Applied Numerical Mathematics, vol. 109, pp. 208-234, 2016.

[11] J. G. McDaniel and W. S. Shepard Jr., "Estimation of structural wave numbers from spatially sparse response measurements," The Journal of the Acoustical Society of America, vol. 108, no. 4, pp. 1674-1682, 2000.

[12] K. Maes, J. Peeters, E. Reynders, G. Lombaert, and G. De Roeck, "Identification of axial forces in beam members by local vibration measurements," Journal of Sound and Vibration, vol. 332, no. 21, pp. 5417-5432, 2013.

[13] S. H. Zhang, Theoretical method for cable damage identification based on bending wave, Ph.D. thesis, Southwest Jiaotong University, Chengdu, China, 2018.

[14] Z. Ti, M. Zhang, Y. Li, and K. Wei, "Numerical study on the stochastic response of a long-span sea-crossing bridge subjected to extreme nonlinear wave loads," Engineering Structures, vol. 196, pp. 1-13, 2019.

[15] M. Zhang, J. Zhang, Y. Li et al., "Multi-site measurement for energy application of small distributed wind farm in complex mountainous areas," Energy Reports, vol. 6, pp. 1043-1056, 2020.

[16] J. Zhang, M. Zhang, Y. Li, J. Qin, K. Wei, and L. Song, "Wind energy assessment for small distributed wind farm in complex mountainous region based on field measurement," Journal of Cleaner Production, vol. 274, Article ID 123036, 2020.

[17] J. Zhang, M. Zhang, Y. Li, and C. Fang, "Comparison of wind characteristics at different heights of deep-cut canyon based on field measurement," Advances in Structural Engineering, vol. 23, no. 2, pp. 219-233, 2020.

[18] J. F. Doyle, Wave Propagation in Structures, Springer, New York, NY, USA, 1989.

[19] U. Lee, J. Kim, and H. Oh, "Spectral analysis for the transverse vibration of an axially moving Timoshenko beam," Journal of Sound and Vibration, vol. 271, no. 3-5, pp. 685-703, 2004.

[20] Z. Chen, R. Yan, H. Liu, and Y. Bu, "Study of a cable force determination method in prestressed steel structures," International Journal of Space Structures, vol. 28, no. 2, pp. 59-73, 2013.

[21] R. Chen, C. F. Wan, S. Xue, and H.-S. Tang, "Modification of motion equation of Timoshenko beam and its effect," Journal of Tongji University (Natural Science), vol. 33, no. 6, pp. 711-715, 2005.

[22] J. B. Zhang, "Dynamic analysis of structures based on spectral element method," Ph. D thesis, Huazhong University of Science \& Technology, Wuhan, China, 2011.
[23] C.-C. Chen, W.-H. Wu, M.-R. Leu, and G. Lai, "Tension determination of stay cable or external tendon with complicated constraints using multiple vibration measurements," Measurement, vol. 86, pp. 182-195, 2016.

[24] S. Li, E. Reynders, K. Maes, and G. De Roeck, "Vibrationbased estimation of axial force for a beam member with uncertain boundary conditions," Journal of Sound and Vibration, vol. 332, no. 4, pp. 795-806, 2013.

[25] L. Wang, R. Shen, S. Zhang, and W. Li, "Characteristics of slip between cable and saddle in suspension bridges," IABSE Symposium Report, vol. 106, no. 4, pp. 843-849, 2016.

[26] H. J. Zhou, Y. H. Wu, L. X. Li, L. M. Sun, and F. Xing, "Free vibrations of a two-cable network inter-supported by crosslinks extended to ground," Smart Structures and Systems, vol. 23, no. 6, pp. 653-667, 2019.

[27] T. Shimada, "Estimating method of cable tension from natural frequency of high mode," Doboku Gakkai Ronbunshu, vol. 1994, no. 501, pp. 163-171, 1994.

[28] R. Geier, G. De Roeck, and J. Petz, "Cable force determination for the danube channel bridge in vienna," Structural Engineering International, vol. 15, no. 3, pp. 181-185, 2018.

[29] X. F. Xie, "The bending stiffness of cable identification method research," Master thesis, Central South University, ChangSha, China, 2012. 